\title{
Game of phones: Integrating mobile technology into science and engineering classrooms
}

\author{
Crump, Vanessa ${ }^{a}$ and Sparks, Julie ${ }^{b}$
}

${ }^{\mathrm{a}}$ Science \& Engineering Program, UTS Insearch, Australia, ${ }^{\mathrm{b}}$ Engineering \& IT Program, UTS Insearch, Australia.

\begin{abstract}
Mobile technologies are ubiquitous in the lives of our students. Rather than seeing the presence of these devices in the classroom as a hindrance or a distraction, educators should embrace the opportunities for greater student engagement, collaboration and useful feedback.

This paper reports some uses of mobile technologies in classrooms at UTS Insearch and the responses of science and engineering students. We hope that our reflections will be a useful guide to other educators and suggest simple ways to integrate flipped learning and gamification into undergraduate classrooms.

UTS Insearch has a blended learning approach to teaching where students learn through seamless integration of technology-enhanced strategies and face-to-face activities. We focus on our experiences using learning tools, such as Kahoot! and Mentimeter, to demonstrate practical applications of gamification in science and engineering classrooms.

The teaching style used in Australian universities incorporating studentcentred flipped learning is foreign to many students, especially those from Non-English Speaking Backgrounds, but data from surveys and reflections allow us to conclude that a majority of students value the use of emerging technologies in learning and that they assist with motivation, formative assessment, collaborative learning and student engagement.
\end{abstract}

Keywords: Mobile technologies in learning; gamification in education; new tools for teaching; engineering and science students; Non-English Speaking Background students; flipped learning. 


\section{Introduction}

This paper reports on the different ways educators can encourage the on-task use of mobile devices through the targeted use of tools such as quizzes, polls and discussion boards.

UTS Insearch is a registered higher education institution and pathway provider to the University of Technology Sydney (UTS). Our students come from various educational backgrounds and over 90 different countries, with most originating from Australia, China, Vietnam, South Korea, Saudi Arabia and Nepal. In the Science and Engineering programs we are responsible for the subjects Introduction to Technical Communication; Engineering Communication; Chemistry 1; and Principles of Scientific Practice.

The response by some schools and universities to the perceived dangers of distraction by mobile device usage in classrooms has been to ban their use. Rather than resisting their presence in classrooms, we offer solutions that allow educators to integrate flipped learning and gamification into lessons. Learning tools such as Kahoot! and Mentimeter can enhance motivation and engagement, provide formative assessment feedback, stimulate discussion and debate and support both independent learning and teamwork.

In this paper, we share some of the ways we implement these learning tools, primarily from our own experience and the perspective of our students. These findings will be of practical interest to educators working in a range of teaching and learning contexts, and at all levels of education, who wish to incorporate mobile technologies into the classroom.

\section{Mobile devices in education}

Smartphones are the mobile device universally used by our students. UTS Insearch has a policy of using blended learning, or a 'flipped', approach to teaching and learning. Students are required to use smartphones, tablets or laptops and encouraged to 'bring your own device' (BYOD) and connect to Wi-Fi to access learning resources and participate in and complete class activities.

While we would not encourage students to record lectures or photograph boards full of notes, we do encourage their use in our classrooms. Students can photograph instructions given informally in class or the working to a problem to refer to later. A photo is a quick and accurate way for a student to record a web address or directions to other resources. We have used mobile devices to send an email to students because we are delayed and want them to remain in class until we get there. Students text each other to let us know they are running late, or cannot find the room. Our students of Non-English Speaking Backgrounds can be observed using Google Translator to check the meaning of words. Data needed for problem-solving, such as the Periodic Table, can be quickly sourced. Students with 
accessibility needs can use mobile devices as assistive technology (AT), with the benefit that this is less stigmatizing than using traditional AT devices (Musti-Rao \& Walker, 2017).

Students from different backgrounds use technology in different ways, and educators must establish expectations around the use of mobile devices in classrooms. We have found that negotiated sensible use is more fruitful than trying to control student behaviour by completely banning mobile phones in classrooms. Smith-Stoner (2012) suggests that some rules are non-negotiable, such as not using mobile devices during tests. Other protocols might include ringers turned off or set to vibrate, students leaving the room to make or receive important calls, having permission to record or photograph anyone in the class and only texting in class if it is relevant (Smith-Stoner, 2012).

We note that the literature reflects a mixed bag of responses from educators and students regarding the benefits of mobile phone use. Walker (2103) reported that students, while acknowledging the potential for distraction and even harm, felt that they benefitted from the use of their devices at school and were creative in finding ways to use their devices educationally. Beland and Murphy (2016) surveyed the literature and concluded the mere presence of technology has a minimum impact on test scores, but that when used purposefully has the potential to enhance student outcomes. However, in two experiments, Ward, Duke, Gneezy, and Bos (2017) demonstrated that the presence of a mobile device nearby was sufficient a distraction to reduce cognitive capability and suggested that potential negative effects on student engagement, learning and test performance merits the cautious use of mobile devices.

We aim to make our lessons engaging and student-centred, so mobile devices are not used as a distraction from boredom but recognise that positive experiences may not be reported by all. Sensible protocols for the use of such devices should be implemented. Nonetheless, we would assert that these technologies provide so many benefits that their use is not to be feared.

\subsection{Mobile technologies - what the literature shows}

Mobile phones have been found to be a powerful tool to support student-centred and directed learning opportunities (Preston et al., 2015) when used to record lectures, instructions for assignments, or to photograph experimental or fieldwork. Another constructive use is for student collaboration (Corbeil \& Valdes-Corbeil, 2007), which is necessary for the successful implementation of active learning. Multiple studies (O'Bannon et al., 2017; Thomas et al., 2014; Purcell et al., 2013) have confirmed that the anywhere, anytime learning opportunities provided by access to the Internet are perceived by both educators and students as the primary benefit of using mobile phones in the classroom. 
In Australia, Farley et al. (2015) found that $87 \%$ of tertiary students favoured the idea of using their mobile devices in or out of class to support their learning. Students used their devices primarily for discussion forums (94\%), and to access lectures slides (90\%). Nonetheless, most in-class use $(61 \%)$ was to access course materials rather than because instructors required their use as part of the in-class activity.

\subsection{Gamification in the classroom}

Kiryakova et al. (2014) assert that students lack engagement and the motivation for active participation in the learning process, but Roblyer (2016) proposed that the appropriate use of technology could overcome this issue. Gamification is the process of adapting a nongame experience, in this case specifically a learning activity, with game-like elements to engage and motivate and promote problem-solving and learning (Kapp, 2012). The key features of gamification are that users are participants; the challenges provided progress towards defined objectives; points are assigned, and users are ranked based on their achievements (Kiryakova et al., 2014).

We see gamification as a key element of flipped learning, and in our experience, it can support group work, active learning and give individualized feedback to students. Information and communications technology can provide tools with strongly competitive game elements to engage students while allowing educators to process students' data, track progress and generate detailed reports. The feedback is useful to students and educators alike. Some of the most popular tools include Quizlet, Kahoot!, Mentimeter and FlipQuiz ${ }^{\mathrm{TM}}$ and are accessed on mobile devices via cloud services, require no special software, and can be used at any time or location where Wi-Fi is available.

\section{Gamification and flipped learning}

Flipped learning was pioneered by Bergman and Sams (2014) to engage students more actively in their learning. Students individually prepare before coming to class using videos or online notes, allowing in-class time to be used for group work and individualised attention. The key elements of flipped learning include flexible spaces, so students choose when and where to learn; a student-centred approach; intentional content; and reflective educator practice (Flipped Learning Network, 2014).

Students at UTS Insearch are drawn from a range of international backgrounds, with many used to a traditional, direct instruction classroom style. They are unused to self-directed learning, collaboration, creative and problem-solving approaches. In other words, they do not expect to have fun. We use several learning tools with elements of gamification to implement flipped learning and student-centred activities in our classrooms, including Kahoot!, and Mentimeter. What do these students think of this use of mobile technologies? 


\subsection{Using Kahoot! in the classroom}

Kahoot! is a learning tool that administers quizzes or surveys to the whole class in real time. It has largely replaced earlier audience response polling tools such as clickers. It is a game-based response system where multiple-choice, true/false or yes/no questions are projected onto the screen. Teachers can easily design and edit quizzes and can embed images or videos. Students log into the learning game and play as individuals, or in teams, answering the questions on smartphones, tablets or laptops. Kahoot! has 70 million monthly users and has been played in 206 countries (Kahoot!, 2017).

We feel that using learning tools, such as Kahoot! presents several advantages for students and educators. It is a low stake, low-risk task and students receive their feedback privately and in real time, thus allowing students the freedom to fail. Students can celebrate their victory when they improve their score or head the leaderboard. The games are social, engaging and entertaining. For educators, the feedback can be used informally to check the understanding of the class broadly. Alternatively, the data can be downloaded, and the responses of an individual student can be analysed or used for assessment purposes. Some of the ways that Kahoot! has been used in our classrooms are detailed below.

Students are asked to watch a video or read a journal article as part of their preparation for class. A Kahoot! quiz is then used at the start of the lesson to check their preparation. We find that this is a reliable way to make students engage with stimulus material in their flipped learning and ensures a better level of preparation for class. Other advantages are that students arrive punctually to class and are immediately engaged as they have to log on quickly in order to participate. The instructor gets immediate feedback on the level of preparation and students who are not prepared are aware their lack of preparedness is noted and recorded. The key concepts previously covered can be summarised before starting new work.

Weekly Kahoot! quizzes are used in Chemistry lectures, usually at the end of a topic, for two reasons. Firstly, they are a way of allowing the lecturer to assess the general understanding of the cohort. Questions are used that will draw out common misunderstandings of concepts. The number of incorrect responses is an indication of the number of students who need to have these misconceptions challenged. The instructor can briefly discuss the concept before continuing the quiz. A similar question can then follow to see if improvement has occurred. Secondly, the student gets immediate, individualized feedback that allows them to see what concepts they have understood and if they are in the majority or minority. The feedback is private; they have not been 'called out' making an error. 
In the Introduction to Technical Communication subject, students choose a creative way to tell the class about their project. Some students use Kahoot! as their delivery method. They create their own questions and thus take ownership of the technology. Student participation rates in either individual or group quizzes are consistently $100 \%$.

At the end of each semester, Chemistry 1 students are asked to reflect on their learning experiences, and these surveys provide a rich source of data. Most students $(n=512)$ report that they found the use of Kahoot! quizzes useful (very useful $=43.9 \%$; somewhat useful $=$ $38.3 \%)$. A handful of students (1.4\%) say they did not participate in these activities, and only $16.4 \%$ felt that Kahoot! quizzes were not very useful.

There are disadvantages to the use of this teaching tool. The nature of the game favours speed and accuracy, and yet a slow and methodical approach to problem-solving is something we encourage in our engineering and science students. We note that not all student responses are positive, that any one type of technology should not be overused. Other students felt that without access to the questions and correct responses later the work could not be reviewed, however this information could be made available to students if necessary. Most students reported the quizzes were enjoyable, motivating and useful for monitoring their progress.

\subsection{Using Mentimeter in the classroom}

Mentimeter is a learning tool that encourages active class participation as students respond anonymously to questions or surveys using multiple-choice, open-ended questions or scales. The instructor can assess the opinions or understanding of students in real time and display the data in tables, charts or word clouds. Mentimeter can be used to elicit feedback, frame discussions, rate solutions or compare work samples. The use of anonymous responses via mobile phones, laptops or tablets encourages greater engagement and a higher participation rate, compared to normal response methods, such as hand-raising. The use of such electronic response systems has been shown to be useful in actively engaging students (Morrison, 2015).

Some of the ways that Mentimeter has been used in our classrooms are detailed below. We have found it positively improves the level of attention and participation in the classroom environment, supports quality learning through encouraging interaction and discussion from even the most introverted students, and gives useful feedback to both the instructor and students.

In the subjects Introduction to Technical Communication and Engineering Communication, students are expected to watch videos that outline the conventions used for referencing. Once in the classroom, students work in pairs to write a correct citation for a book. They 
use the UTS Library website and interactive referencing guide and submit their answers via Mentimeter. Together the class decides which citations have obvious errors and these are removed. A second round uses a journal article, as these are more complex to reference. There are fewer errors as students develop their mastery of this skill.

One of the grading criteria for a task in Introduction to Communication is assessing how engaging the presentation was for the audience. Students use Mentimeter to vote and rank the top three presentations. Students do not have to reveal their votes publicly, so the feedback is assumed to be more honest than a paper vote or show of hands. Students value the real-time feedback given immediately after presentations are delivered. The overall ranking is used to assign the grades for this criterion, and Mentimeter results have consistently matched the overall opinion of the Tutor, indicating student honesty in voting.

Principles of Scientific Practice students explore an ethical scenario and in small groups weigh the advantages and disadvantages of a variety of possible responses. Mentimeter is used for consensus building and to rank the preferences and establish the majority view.

\subsection{Other mobile technologies}

Google Forms and SPARK ${ }^{\text {PLUS }}$ - These educational technologies are used in our subjects for self and peer assessment. Students often feel that group work assessment can lead to students receiving equal marks for unequal contributions. Using these technologies allows students to rate the contributions of their peers confidentially. As with Mentimeter, we believe that using these types of technologies results in more honest and thoughtful responses. Another advantage for educators is the ease with which forms can be set up, modified and reused. Summaries of the data are easily accessed and analysed via software, such as Excel.

Videos, E.g. TED talks - During twenty-minute breaks in three-hour workshops, students were observed to be watching video clips on their phones. This 'wasted' time is now used by students to watch an assigned clip, such as a TED talk. The presentations are chosen because they are controversial and will spark a debate. The students are asked questions on their return and expected to justify their opinion. In their reflections, students report their enjoyment of these discussions and clearly relish the challenges they present.

\section{Conclusion}

Mobile technology surrounds us and is assumed to be a backdrop to the learning environment. Although educators sometimes witness circumstances where mobile devices cause distractions, our experiences show there are many opportunities for incorporation of gamification and mobile technology in conventional and flipped-learning classrooms. Clear 
guidelines for the use of this technology should be established. Positive applications of mobile technologies include polling, quizzes, access to videos and search engines and photographing information or results. This is a rapidly developing area, but our experience has shown that embracing this technology is positive for student engagement and learning and provides rich feedback to the educator.

\section{References}

Beland, L. P., \& Murphy, R. (2016). Ill communication: technology, distraction \& student performance. Labour Economics, 41, 61-76.

Bergmann, J., \& Sams, A. (2014). Flipped learning: Gateway to student engagement. International Society for Technology in Education.

Corbeil, J., \& Valdes-Corbeil, M. (2007). Are you ready for mobile learning? EDUCAUSE Quarterly, 30(2), 51-58.

Farley, H., Murphy, A., Johnson, C., Carter, B., Lane, M., Midgley, W., ... \& Koronios, A. (2015). How do students use their mobile devices to support learning? A case study from an Australian regional university. Journal of Interactive Media in Education, 2015(1).

Kahoot! (2017). New year, new heights: Kahoot! grows by $75 \%$ to reach 70 million unique users Retrieved from https://kahoot.com/press/2018/01/18/kahoot-grows-reach-70million-unique-users/

Kapp, K. (2012). The gamification of learning and instruction: Game-based methods and strategies for training and education. John Wiley \& Sons

Kiryakova, G., Angelova, N., \& Yordanova, L. (2014). Gamification in education. Proceedings of 9th International Balkan Education and Science Conference.

Mentimeter (n.d.) Guides Retrieved from https://www.mentimeter.com/guides

Morrison, J., (2015). The effects of electronic response systems on student learning.

Musti-Rao, S. \& Walker, Z. (2017). Use of mobile technology in the classroom. Retrieved from http://www.council-forlearning-disabilities.org/infosheets-supporting-translationof-research-to-practice.

Network, F. L. (2014). The four pillars of FLIP.

O'Bannon, B., Waters, S., Lubke J., Cady, J. \& Rearden, K. (2017). Teachers and students poised to use mobile phones in the classroom, Computers in the Schools, 34(3), 125-141

Preston, J., Wiebe, S., Gabriel, M., McAuley, A., Campbell, B., \& McDonald, R. (2015). Benefits and challenges of technology in high schools: a voice from educational leaders with a Freire echo. Interchange, 46 (2), 169-185.

Purcell, K., Heaps, A., Buchanan, J., \& Friedrich, L. (2013). How teachers are using technology at home and in their classrooms. Washington, DC: Pew Research Center's Internet \& American Life Project.

Roblyer, M., (2016). Integrating educational technology into teaching (7th ed.). Boston, MA: Pearson. 
Smith-Stoner, M. (2012). Class is about to start: please turn on your cell phones: 10 uses for cell phones in nursing education. Teaching and Learning in Nursing, 7(2), 42-46.

Thomas, K., O'Bannon, B., \& Britt, V. (2014). Standing in the schoolhouse door: teacher perceptions of mobile phones in the classroom. Journal of Research on Technology in Education, 46(4), 373-395.

Ward, A. F., Duke, K., Gneezy, A., \& Bos, M. W. (2017). Brain drain: the mere presence of one's own smartphone reduces available cognitive capacity. Journal of the Association for Consumer Research, 2(2), 140-154. 